\title{
Metode Penginjilan Melalui Kegiatan Belajar Mengajar di Rumah Singgah
}

\author{
Lucky Antonio \\ Sekolah Tinggi Teologi Kerusso Indonesia, Bekasi \\ luckyantonio@gmail.com
}

\begin{abstract}
Evangelism is always associated with the Great Commission of the Lord Jesus, in a pluralistic nation like Indonesia, where there are various ethnic groups and religions, the method of evangelism must be adapted to the cultural context and diversity. The concept of evangelism through teaching and learning activities is one way of approaching evangelism. Apart from opening service posts, this method is quite effective. The approach taken does not only emphasize spiritual matters or activities, but also provides for teaching and education needs. So that the need for education, learning and spirituality is met.
\end{abstract}

Keywords:concepts; education; evangelism; teaching and learning

\begin{abstract}
Abstrak
Penginjilan selalu dikaitkan dengan Amanat Agung Tuhan Yesus, di dalam bangsa yang menjemuk seperti Indonesia, di mana terdapat berbagai macam suku bangsa dan agama, metode penginjilan harus disesuaikan dengan konteks budaya dan keragaman. Konsep penginjilan melalui kegiatan belajar mengajar menjadi salah satu cara pendekatan dalam melakukan penginjilan. Selain dengan pembukaan pos-pos pelayanan, cara ini cukup efektif. Pendekatan yang dilakukan tidak hanya menekankan pada hal atau kegiatan rohani saja, tetapi juga memberikan kebutuhan akan pengajaran dan pendidikan. Sehingga terpenuhi kebutuhan akan pendidikan, pembelajaran dan kerohanian.
\end{abstract}

Kata kunci: belajar mengajar; konsep; pendidikan; penginjilan

\section{PENDAHULUAN}

Tuhan Yesus menyatakan dengan jelas dalam mandat atau amanat agung yang diberikan kepada kita, seperti yang tercantum di dalam Matius 28:19-20, "Karena itu pergilah, jadikanlah semua bangsa murid-Ku dan baptislah mereka ke dalam nama Bapa, dan Anak dan Roh Kudus, dan ajarlah mereka melakukan segala sesuatu yang telah Kuperintahkan kepadamu, ketahuilah Aku menyertai engkau sampai akhir zaman." Kata 'ajarlah' menurut ayat tersebut mencakup membangun kognitif, afektif, psikis, dan intelektual manusia. Perkataan-perkataan-Nya dalam pelayanan tidak secara verbal saja tetapi juga tindakan nyata yang dinamis. David J Bosch mengatakan bahwa penginjilan selalu melalui dua aspek yakni verbal dan non-verbal. ${ }^{1}$

Tidak ada satu cara yang tunggal untuk bersaksi tentang Kristus. Karenanya Firman Tuhan

\footnotetext{
${ }^{1}$ David J Bosch, Transformasi Misi Kristen, Jakarta : BPK Gunung Mulia,2000, hal 643
} 
tidak bisa dipisahkan dari perkataan, perbuatan, teladan hidup dan iman Kristiani dalam kehidupan sehari-hari. Sebab Injil adalah Firman yang menjadi daging. Perbuatan tanpa kata-kata adalah bisu, kata-kata tanpa perbuatan ialah kosong. Sejarah Alkitab mencatat bahwa kaum miskin dan kelompok-kelompok marginal ini menarik perhatian khusus Yesus dan para rasul dalam pemberitaan Injil. Lukas salah seorang murid-Nya mempunyai perhatian terhadap kaum papa ini. Sebagaimana tertulis di dalam Lukas 1:53, "Ia melimpahkan segala yang baik kepada orang yang lapar, dan menyuruh orang kaya pergi dengan tangan hampa.",

Perasaan ini dipertahankan oleh Lukas dalam Injilnya. Karena itu misi Kristen sesungguhnya memiliki dimensi sosial yang kuat. Menurut Emmanuel Gerrit Singgih:

Kalau melihat urutan pelayanan Yesus maka terlebih dulu Yesus memberikan amanat agar orang Kristen memperhatikan orang miskin, karena perhatian mereka orang miskin sama dengan ibadah kepada Yesus (Matius 25 : 31-46). Kemudian baru Yesus memberi mandat kepada murid-murid-Nya untuk melaksanakan amanat yang sesungguhnya (Matius 28:1620). Gereja harus menjadi Injili tetapi juga berwawasan sosial. ${ }^{2}$

Yesus menyatakan pelayanan yang mempunyai nilai kerohanian dan kemanusiaan adalah pelayanan yang bersifat holistik artinya: suatu pendekatan yang menyeluruh terhadap manusia guna memperoleh segala hal yang berkaitan dengan manusia itu sendiri. Yesus dalam mewartakan Kerajaan Allah kepada kaum miskin tidak hanya dalam kata-kata, tetapi dalam tindakan yang penuh dengan kuasa: menyembuhkan orang sakit, menghibur yang menderita, memberi makan bagi mereka yang kelaparan, mengusir setan-setan, membangkitkan orang mati, bahkan '’Ia rela menjadi miskin, sekalipun ia kaya' (II Korintus 8:9).

Pada dasarnya, orang yang dikatakan miskin adalah orang yang serba berkekurangan dalam hidupnya, tidak berharta dan biasa tinggal dan hidup di dalam lingkungan yang kumuh. Seorang tokoh theologia pembebasan bernama Gustavo Guttirrez menyebut kemiskinan sebaagai suatu "estado escandoloso" atau keadaan tidak terhormat. ${ }^{3}$ Keadaan orang miskin pada umumnya tidak terhormat dan jauh dari kehidupan khalayak ramai pada umumnya, dan juga seringkali orang lain enggan bila berkunjung atau bertamu di rumahnya, dikarenakan kondisi lingkungan dan pemukiman yang kumuh tersebut.

Dalam realitas kehidupan di ibukota negara di Indonesia, yaitu Jakarta yang sering dijuluki kota metropolitan namun yang oleh karena pesatnya pembangunan dan perkembangan dalam segala bidang, maka Jakarta telah menjadi kota megapolitan yang lebih menonjolkan kebesaran, kemewahan dan kemegahan, namun dibalik dinding semua yang serba mewah dan megah itu kenyataannya masih ada sekian banyak masyarakat yang hidup di bawah garis kemiskinan, terdapat jurang yang dalam antara golongan menengah ke atas dengan golongan menengah ke bawah. Mereka tak hanya miskin tapi mereka juga sengsara dan menderita, baik secar fisik

${ }^{2}$ Emmanuel Gerrit Singgih, Tempat dan Arah Gerakan Oikumenis, Jakarta : BPK Gunung Mulia, 1994, hal 24

\footnotetext{
${ }^{3}$ Yewanggoe, Kemiskinan Dan Etos Kerja Masyarakat Indonesia, Jakarta : Yakoma, 1992, hal 209
} 
maupun jiwa. Sebagian dari mereka untuk menutupi kebutuhan hidup sehari-hari saja sangat bergantung pada uluraan tangan dan belas kasihan atau kepedulian dari orang-orang yang standar hidupnya di atas mereka. Memang kemiskinan sangat sulit untuk dihapuskan, selalu ada dimana-mana dari sejak dahulu sampai sekarang, Yesus berkata, dalam Matius 26:11. Karena orang-orang miskin selalu ada padamu. Dalam penelitian ini kata yang dipakai sebagai pengganti kata orang miskin adalah kaum marginal.

Sebagai kaum marginal, mereka sangat kurang memperhatikan pendidikan anak-anak mereka. Walaupun memang tidak semua demikian. Tentunya karena uang yang lebih diutamakan untuk kebutuhan yang lebih prioritas, yaitu makan. Tak jarang orangtua memaksa anak-anaknya untuk bekerja mencari uang daripada duduk di bangku sekolah. Apabila mereka tidak dapat memenuhi kebutuhan hidup sehari-hari, maka mereka tidak segan-segan melakukan tindak kejahatan, seperti pencurian, penjambretan, penodongan bahkan perampokan yang tentunya akan menggiring mereka masuk dalam jeruji besi, jika tertangkap. Mengenai tempat tinggal biasanya mereka menghuni tempat-tempat kumuh yang tidak layak untuk huni seperti di kawasan bantaran sungai, sepanjang jalur rel kereta api, kolong-kolong jembatan, tempat pembuangan akhir sampah bahkan sampai di tempat seperti TPU (taman pemakaman umum) dan sebagainya. Mereka akan membuat rumah dari barang-barang bekas yang diperoleh dari tempat pembuangan sampah tanpa harus membeli bahan-bahan yang mahal, mereka menggunakan sengseng bekas dan kardus-kardus bekas, papan bekas sebagai bahan untuk 'rumah' mereka.

Untuk menghadirkan Injil sebagai berita sukacita dalam kehidupan kaum marginal ini, ada berbagai cara dan metode yang dapat dilakukan. Salah satu metode ialah melalui pendidikan di luar sekolah. Inilah metode yang dilakukan di Pos-pos Pelayanan Rumah Pelangi di seantero Jakarta, yang terbagi dalam lima wilayah, Utara, Barat, Selatan, Timur dan Pusat.

Adapun latar belakang beridirinya Pos Pelayanan Rumah Pelangi, adalah adanya dorongan hati atau tuntunan dari Roh Kudus untuk membawa berita keselamatan kepada kelompok marginal ini. Dalam perkembangan selanjutnya, pelayanan ini memiliki visi untuk menciptakan penginjil-penginjil yang muncul dari kalangan mereka untuk bergerak memberitakan berita sukacita atau warta keselamatan di kalangan kaum marginal itu sendiri. Berdasarkan hal tersebut maka Tim Pelayanan Pelangi (Pelangi = Peduli Anak Bangsa Indonesia) memilih metode penginjilan melalui proses belajar mengajar di pos pelayanan Rumah Pelangi dengan tujuan: mencerdaskan kehidupan anak bangsa dan sekaligus memberitakan Injil sebagai kabar baik bagi kaum marginal agar mereka menerima keselamatan di dalam Tuhan Yesus sehingga mempunyai pengharapan untuk masa depan yang lebih cerah.

Namun metode yang dilakukan seringkali cenderung kurang bersifat holistik, hal ini dapat dilihat pada metode pendekatan melalui pemberian materi berupa pemberian makanan, sembako atau pakaian sehingga kurang memprioritaskan penginjilan itu sendiri, bahkan tak jarang terjebak pada kecenderungan penginjilan dilakukan hanya sebagai salah satu bentuk pelayanan sosial. Di sisi yang lain, metode penginjilan terlalu menekankan pada proses pendampingan yang bersifat 
spiritual sehingga berakibat pendidik cenderung mengabaikan bahwa manusia juga membutuhkan bantuan secara jasmani yaitu sandang dan pangan untuk menunjang kehidupan sehari-hari.

\section{METODE PENELITIAN}

Metode penelitian dalam artikel ini adalah deskriptif. Melalui pendekatan kualitatif literatur menggunaakn berbagai sumber kepustakaan untuk memperoleh pemahaman tentang penginjilan secara biblikal dan kaitannya dengan kegiatan sosial dalam bentuk belajar.

\section{PEMBAHASAN}

Pada hakekatnya penginjilan ialah bagian hakiki dari gereja. Namun faktanya terdapat banyak kebingungan dalam pemahaman mengenai penginjilan. Penginjilan atau evangelism, berasal dari kata dalam bahasa Yunani yakni "Euangelion" yang berarti good news atau kabar baik. Kabar baik yang dimaksud adalah Injil, The Gospel, yang berisi berita keselamatan, berita pengampunan, berita perdamaian, dan berita pengudusan bagi orang berdosa. Kabar baik adalah anugerah yang dapat diperoleh melalui Yesus Kristus, dan dengan iman kepada-Nya orang berdosa mendapatkan hidup kekal."4 Jadi penginjilan adalah menyampaikan kabar baik atau berita keselamatan mengenai kematian dan kebangkitan Yesus Kristus bagi orang berdosa.

Bagi orang Kristen, inti kabar baik adalah Yesus Kristus. Bertolak dari hal ini maka penginjilan secara sederhana dapat didefinisikan sebagai perintah Tuhan kepada hamba-hambaNya untuk memberitakan kabar baik di dalam nama-Nya kepada orang-orang berdosa untuk mengalami pertobatan dan menerima keselamatan kekal. Eunggalion pada awalnya adalah istilah yang dipakai dalam kemiliteran yaitu upah yang diberikan kepada seseorang yang membawa berita kemenangan dari medan pertempuran kemudian kata tersebut berkembang menjadi berita kemenangan. Pada saat Alkitab Perjanjian Baru ditulis, para penulisnya meminta istilah itu untuk menjelaskan cerita kabar baik dari Tuhan, tentang Yesus Kristus dengan karya keselamatan bagi seluruh dunia. Jadi pengertian penginjilan ialah kegiatan pemberitaan Injil untuk melaksanakan perintah Tuhan bagi semua orang percaya agar setiap orang dilepaskan dari semua ikatan dengan kuasa-kuasa kegelapan dan dibawa masuk ke dalam terang-Nya yang ajaib yaitu kehidupan kekal di dalam Tuhan Yesus Kristus.

\footnotetext{
${ }^{4}$ Makmur Halim, Model-model Penginjilan Yesus Suatu Penerapan Masa Kini, Malang: Gandum Mas, 2003, hal 25
} 
Dalam perkembangan selanjutnya, timbul beragam pemahaman seputar penginjilan. Mengapa hal ini terjadi? Dari berbagai pendapat ada satu hal yang utama yaitu kebiasaan orang untuk mendefinisikan penginjilan bukan berdasarkan berita Injil sendiri tetapi berdasarkan pengaruh yang dihasilkan terhadap pendengar Injil dengan kata lain penginjilan terlalu menekankan segi pertobatan dari orang-orang yang mendengarkannya. Apakah Injil sudah disampaikan secara baik dan benar atau belum? Lalu bagaimana definisi yang benar tentang penginjilan? Pertama yang harus diingat ketika mendefinisikan tentang penginjilan adalah jangan mengabaikan peran Tuhan di dalamnya. Mengapa demikian? Karena penginjilan itu pada hakekatnya adalah inisiatif dan prakarsa dari Tuhan sendiri. Manusia hanya pelaksana prakarsa Tuhan tersebut. Berikut dikemukakan definisi menurut para Teolog :

Henk Venema mengatakan:

Penginjilan adalah implikasi dan penerapan mandat yang diberikan oleh Yesus kepada murid-murid-Nya, menjadi pemberita kabar baik sampai ke ujung-ujung bumi. Dalam melaksanakan mandat dan perintah melalui iman pengakuan dosa dan pertobatan meninggalkan hidup yang lama, orang-orang berdosa dimasukkan ke dalam jemaat Kristus oleh baptisan dan belajar melakukan segala sesuatu yang diperintahkan oleh Yesus Kristus kepada mereka semua, dengan tujuan supaya Allah Tritunggal menerima pujipujian yang sepatutnya secara kekal dari kehidupan J.H. Bavinck : Penginjilan ialah kegiatan gereja yang sebenarnya tidak lain dari kegiatan besar Kristus sendiri yang dilakukan-Nya melalui gereja yaitu pada masa ini. Gereja memanggil bangsa-bangsa supaya mereka bertobat dan percaya kepada Kristus dan dijadikan murid-Nya dan oleh baptisan dimasukkan ke dalam persekutuan semua orang yang menantikan kedatanganNya. $^{5}$

David J . Bosch mengungkapkan: "Penginjilan adalah rencana dan progam Allah yang melibatkan orang-orang percaya tentang apa yang telah, sedang dan akan diperbuat Allah untuk keselamatan umat manusia yang kekal." ${ }^{6}$ Sementara Yakob Tomatala berkata: "Penginjilan adalah rancangan dan karya kasih Allah dengan maksud dan tujuan agar manusia berkumpul, bersatu dalam nama-Nya dan memuji dan menyembah-Nya dalam roh dan kebenaran."77 Menurut Peter Wagner,

Penginjilan adalah pemberitaan kabar baik kepada semua umat manusia yang belum mengenal Tuhan secara pribadi. Tujuan dari pekabaran Injil adalah untuk memberi kesempatan kepada semua individu supaya mereka mempunyai kesempatan yang

\footnotetext{
${ }^{5}$ Ibid, hal 18

${ }^{6}$ David J. Bosch. Transformasi Misi Kristen, Jakarta : BPK Gunung Mulia , 2002, hal 123

${ }^{7}$ Peniel, C. D Mawaleng. Beritakan Injil Sampai Ke Ujung Bumi, Makassar: STT Jeffray, 2016, hal 55.
} 
memadai untuk menerima Yesus Kristus sebagai Juru Selamat atas semua dosa-dosa yang telah diperbuatnya dan melayani-Nya dalam persekutuan dengan gereja-Nya. ${ }^{8}$

Menginjil selanjutnya berarti menghadirkan Yesus Kristus dalam kuasa Roh Kudus sedemikian rupa sehingga manusia menjadi percaya kepada Tuhan melalui Yesus sebagai Juru Selamat dan melayani Yesus Kristus sebagai Raja di dalam persekutuan dengan gereja-Nya. Tetapi menurut J.J. Packer definisi di atas berarti menyampaikan berita yang spesifik dengan aplikasi yang spesifik dan menitikberatkan pada hasil penginjilan yaitu pertobatan. Karena itu ia memberikan definisi penginjilan yang baru yaitu:

Penginjilan berarti memberitakan kabar baik. Penginjilan ialah komunikasi yang dilakukan oleh orang Kristen sebagai penyambung lidah Allah yang menyampaikan berita pengampunan kepada orang berdosa. Barangsiapa menyampaikan berita ini dengan setia dalam situasi apapun dalam kumpulan besar/ kumpulan kecil, dari mimbar atau dalam percakapan pribadi maka ia sedang menginjil. ${ }^{9}$

Keberhasilan dan kegagalan seseorang murid berasal dari pribadi murid tersebut. Usaha apapun harus dimulai dari sikap dan cara berpikir dalam menanggapi berbagai situasi yang akan ditemui dalam kehidupan. Setiap orang mempunyai kelebihan serta kekurangan dan semua tinggal bagaimana bisa mengoptimalkan potensi kelebihan tersebut dan meminimalisir kekurangan yang dimilikinya. Keseimbangan semua unsur di dalam diri adalah kunci sukses yang diraih. Belajar merupakan proses perubahan perilaku karena pengalaman dan latihan. Arti lain dari belajar ialah semua aktivitas mental atau psikis yang terjadi dalam interaksi aktif pada lingkungan yang menghasilkan perubahan-perubahan dalam pengelolaan pengertian. Sedangakan pendapat yang lain menyatakan bahwa belajar adalah proses perbuatan yang dilakukan dengan cara sengaja yang kemudian menimbulkan perubahan yang keadaannya berbeda dari perubahan yang dihasilkan.

Pengertian belajar-mengajar, merupakan sejenis perubahan yang diperlihatkan dalam perubahan tingkah laku yang keadaannya tidak sama dari sebelum individu berada pada situasi belajar serta setelah melakukan tindakan yang serupa tersebut. Ada beberapa pengertian yang dipakai untuk menjelaskan pengertian belajar mengajar. Pada definisi klasik menyatakan bahwa

\footnotetext{
${ }^{8}$ Peter Wagner, Gereja Anda Dapat Bertumbuh, Jakarta : Immanuel, 1998, hal 40

9 J.J Packer, Evangelism and The Sovereignity, Surabaya : Momentum, 2003, hal 28
} 
mengajar bisa diartikan sebagai penyampaian sejumlah ilmu karena pandangan yang seperti ini. Guru dianggap sebagai sumber pengetahuan dan siswa dianggap tidak mengerti apa-apa. Pengertian klasik ini sejalan dengan dengan pandangan Bruner yang mempunyai pendapat bahwa mengajar adalah menyampaikan ide, masalah atau pengetahuan dalam bentuk sederhana sehingga bisa dipahami oleh murid. Jerome S. Bruner Pengertian belajar-mengajar dalam definisi modern menolak tentang pandangan klasik dan oleh sebab itu pandangan tersebut mulai kini mulai diabaikan. Kini orang mulai beralih ke pandangan bahwa mengajar tidak sekedar menyampaikan ilmu, tetapi berusaha membuat suatu situasi lingkungan yang memungkinkan murid untuk belajar. Sebuah konsep baru tentang mengajar menyatakan bahwa mengajar merupakan pembinaan bagi siswa bagaimana belajar dan bagaimana berfikir serta menyelidiki.

Dari hal tersebut dapat dipahami bahwa aktivitas yang sangat menonjol dalam pengajaran ada dalam diri seorang murid yang sedang dalam proses pembelajaran. Tetapi tidak berarti peran guru tersisihkan namun diubah. Guru dianggap sebagai sumber pengetahuan sehingga guru selalu aktif dan siswa selalu pasif di dalam kegiatan belajar-mengajar.

\section{KESIMPULAN}

Metode penginjilan dengan membuka rumah singgah dan memberikan pelayanan belajarmengajar bagi kaum yang termarginalkan menjadi sebuah metode penginjilan yang baru, mereka mendapat pelajaran tambahan di luar bangku sekolah tanpa dipungut biaya. Dengan metode ini penginjian tidak hanya menyentuh hal kerohanian saja, tetapi juga tentang hal pendidikan. Penginjilan yang disertai dengan kegiatan belajar mengajar sangat ideal dan cocok dengan situasi dan kondisi kota Jakarta. Walaupun tetap ada kendala-kendala yang dihadapi. Tetapi hal itu tidak membuat kegiatan penginjilan dengan kegiatan belajar mengajar terhenti dan terhalangi.

\section{REFERENSI}

Arliyanus Larosa, M.Th. Memuridkan Dunia Melaksanakan Amanat Agung. Yayasan Kalam Hidup, Bandung. 2005

Bonnke, Reinhard, Penginjilan Dengan Kuasa Roh Kudus - Kunci-kunci Efektif Untuk Menjangkau Jiwa-jiwa Dengan Injil, Jakarta : Light Publishing, 2011 , Penginjilan Dengan Api. Jakarta: Yayasan Pekabaran Injil Immanuel, 1978.

Bosch, David J. Transformasi Misi Kristen, Jakarta : BPK Gunung Mulia, 2000

Dwiraharjo, Susanto. "Kajian Eksegetikal Amanat Agung Menurut Matius 28 : 18-20.” Jurnal Teologi Gracia Deo 1, no. 2 (2019): 56-73. http://sttbaptisjkt.ac.id/ejournal/index.php/graciadeo. 
Hartono, Handreas. "Mengaktualisasikan Amanat Agung Matius 28: 19-20 Dalam Konteks Era Digital.” KURIOS (Jurnal Teologi dan Pendidikan Agama Kristen) 4, no. 2 (2018): 157166.

Halim, Makmur Model-model Penginjilan Yesus Suatu Penerapan Masa Kini, Malang : Gandum Mas, 2003

Manurung, Kosma. "Efektivitas Misi Penginjilan Dalam Meningkatkan Pertumbuhan Gereja." DUNAMIS: Jurnal Teologi dan Pendidikan Kristiani 4, no. 2 (2020): 225-233.

Munthe, Eben. "Mengoptimalkan Karunia Dalam Jemaat Untuk Melakukan Misi Amanat Agung Di Era 4.0.” EPIGRAPHE: Jurnal Teologi dan Pelayanan Kristiani 3, no. 2 (2019): 133.

Packer, J.I, Penginjilan dan Kedaulatan Allah, Jakarta : Momentum Literatur, 2009

Peniel, C. D Mawaleng. Beritakan Injil Sampai Ke Ujung Bumi, Makassar : STT Jeffray, 2016

Peter Wagner, Gereja Anda Dapat Bertumbuh, Jakarta : Immanuel, 1998

Saptono, Yohanes Joko. "Pentingnya Penginjilan Dalam Pertumbuhan Gereja." DIEGESIS: Jurnal Teologi Kharismatika 2, no. 1 (2019): 12-24.

Siahaya, Johannis. "Misi Dalam Doa Yesus Menurut Yohanes 17." Jurnal Teruna Bhakti 1, no. 2 (2019): 19-20. http://e-journal.stakterunabhakti.ac.id/index.php/teruna/issue/archive.

Singgih, Gerrit Emmanuel, Tempat dan Arah Gerakan Oikumenis, Jakarta : BPK Gunung Mulia, 1994

Subekti, Tri. "Pemuridan Misioner Dalam Menyiapkan Perluasan Gereja Lokal." EPIGRAPHE: Jurnal Teologi dan Pelayanan Kristiani (2019).

Tomatala, Y. Y. Penginjilan Masa Kini. Malang: Gandum Mas, 1997.

Widjaja, Fransiskus Irwan. Misiologi Antara Teori, Fakta Dan Pengalaman. 1st ed. Yogyakarta: Andi Offset, 2018.

Wiryadinata, Halim. "Mission And Evangelism : African Context." KURIOS (Jurnal Teologi dan Pendidikan Agama Kristen) 3, no. 1 (2015): 1-11. http://www.sttpb.ac.id/ejournal/index.php/kurios. 